\title{
Comparative analysis on surface property in anodic oxidation polishing of reaction-sintered silicon carbide and single-crystal $4 \mathrm{H}$ silicon carbide
}

\author{
Xinmin Shen ${ }^{1} \cdot$ Qunzhang $\mathrm{Tu}^{1} \cdot$ Hui Deng ${ }^{2} \cdot$ Guoliang Jiang ${ }^{1} \cdot$ Xiaohui He $^{1}$ • \\ Bin Liu ${ }^{1} \cdot$ Kazuya Yamamura ${ }^{2}$
}

Received: 9 June 2015/ Accepted: 20 November 2015/Published online: 10 March 2016

(c) The Author(s) 2016. This article is published with open access at Springerlink.com

\begin{abstract}
For effective machining of difficult-to-machine materials, such as reaction-sintered silicon carbide (RS$\mathrm{SiC}$ ) and single-crystal $4 \mathrm{H}$ silicon carbide $(4 \mathrm{H}-\mathrm{SiC})$, a novel polishing technique named anodic oxidation polishing was proposed, which combined with the anodic oxidation of substrate and slurry polishing of oxide. By scanning electron microscopy/energy-dispersive X-ray spectroscopy (SEM-EDX) observation and atomic force microscopy analysis, both the anodic oxidation behaviors of RS-SiC and 4H-SiC were investigated. Through comparison of the surfaces before and after hydrofluoric acid etching of the oxidized samples by the scanning white light interferometry (SWLI) measurement, the relationships between oxidation depth and oxidation time were obtained, and the calculated oxidation rate for RS-SiC was $5.3 \mathrm{~nm} / \mathrm{s}$ and that for $4 \mathrm{H}-\mathrm{SiC}$ was $5.8 \mathrm{~nm} / \mathrm{s}$ based on the linear DealGrove model. Through anodic oxidation polishing of RS$\mathrm{SiC}$ substrate and $4 \mathrm{H}-\mathrm{SiC}$ substrate, respectively, the surface roughness rms obtained by SWLI was improved to $2.103 \mathrm{~nm}$ for RS-SiC and to $0.892 \mathrm{~nm}$ for $4 \mathrm{H}-\mathrm{SiC}$. Experimental results indicate that anodic oxidation polishing is an effective method for the machining of RS-SiC and $4 \mathrm{H}-\mathrm{SiC}$ samples, which would improve the process level of $\mathrm{SiC}$ substrates and promote the application of $\mathrm{SiC}$
\end{abstract}

Xinmin Shen

shenxmjfjlgdx2014@163.com

1 Research Center for Mechanical and Electrical Engineering, College of Field Engineering, PLA University of Science and Technology, Nanjing 210007, Jiangsu, China

2 Research Center for Ultra-Precision Science and Technology, Graduate School of Engineering, Osaka University, 2-1 Yamadaoka, Suita 565-0871, Osaka, Japan products in the fields of optics, ceramics, semiconductors, electronics, and so on.

\section{Introduction}

Silicon carbide $(\mathrm{SiC})$ is a promising material for semiconductors, ceramics, and optics [1, 2], since it has remarkable excellent mechanical and chemical properties $[3,4]$. In the SiC family, reaction-sintered silicon carbide (RS-SiC) and single-crystal $4 \mathrm{H}$ silicon carbide $(4 \mathrm{H}-\mathrm{SiC})$ have attracted widely interests for their extraordinary capabilities. Besides the common excellences, RS-SiC has the unique advantage of a low manufacturing cost, which makes it an ideal mirror material for space telescope systems $[5,6]$. Meanwhile, $4 \mathrm{H}-\mathrm{SiC}$ is one of the most attractive semiconductor materials for the next-generation power device applications, as it has outstanding electronic properties [7].

However, SiC is a difficult-to-machine (DTM) material because of its high hardness and chemical inertness [8]. Although ultrasmooth $4 \mathrm{H}-\mathrm{SiC}$ surface can be obtained in chemical mechanical polishing (CMP) [9], plasma-assisted polishing (PAP) [10], and CAtalyst-Referred Etching (CARE) [11], the material removal rates (MRR) in these techniques are low. As the composition and structure of RS-SiC are not uniform [12], few of the techniques which have been developed to process $\mathrm{RS}-\mathrm{SiC}$ substrates can yield smooth surface and obtain high material removal rate simultaneously [13].

Anodic oxidation has been developed for the oxidation of silicon, and we applied it to process $\mathrm{SiC}$ [14]. By applying a mixture of hydrogen peroxide $\left(\mathrm{H}_{2} \mathrm{O}_{2}\right)$, hydrochloric acid $(\mathrm{HCl})$, and ultrapure water $\left(\mathrm{H}_{2} \mathrm{O}\right)$ as the electrolyte, both the RS-SiC and $4 \mathrm{H}-\mathrm{SiC}$ were oxidized. 
Afterward, the scanning electron microscopy/energy-dispersive X-ray spectroscopy (SEM-EDX) observation and atomic force microscopy (AFM) analysis were conducted to investigate the oxidation behaviors of $\mathrm{RS}-\mathrm{SiC}$ and $4 \mathrm{H}-$ $\mathrm{SiC}$, respectively. Through comparing the surfaces before and after hydrofluoric acid (HF) etching of the oxidized samples, the relationships between oxidation depth and oxidation time for $\mathrm{RS}-\mathrm{SiC}$ and $4 \mathrm{H}-\mathrm{SiC}$ were obtained. By applying anodic oxidation polishing, the RS-SiC and $4 \mathrm{H}-$ $\mathrm{SiC}$ surfaces in four scenarios which are before oxidation, after oxidation, after simultaneous oxidation-assisted polishing (SOAP), and after divided oxidation-assisted polishing (DOAP) were analyzed comparatively. By calculation of oxidation rate based on the Deal-Grove model [15] and comparison of surface quality, the superiority of anodic oxidation polishing of $\mathrm{SiC}$ substrates was revealed.

\section{Experimental apparatus and parameters}

Schematic diagrams of the anodic oxidation system and the anodic oxidation polishing system are shown in Fig. 1a, b, respectively. The electrolyte used in the anodic oxidation system was a mixture of $\mathrm{H}_{2} \mathrm{O}_{2}, \mathrm{HCl}$, and $\mathrm{H}_{2} \mathrm{O}$, and the composition proportion was $\mathrm{H}_{2} \mathrm{O}_{2}: \mathrm{HCl}: \mathrm{H}_{2} \mathrm{O}=15: 5: 80$. The power supply was a three-phase potentiostat, and the oxidation potential was $9.8 \mathrm{~V}$. The cathode, anode, and reference electrode were platinum $(\mathrm{Pt}), \mathrm{SiC}$, and $\mathrm{Ag} / \mathrm{AgCl}$, respectively.

For the anodic oxidation polishing of $\mathrm{SiC}$ samples, the experimental parameters are summarized in Table 1. The electrical source was consisted of a digital function generator and a bipolar power supply, and a digital storage oscilloscope was used to observe the status of the oxidation circuitry. The ceria $\left(\mathrm{CeO}_{2}\right)$ slurry was used as the electrolyte. The $\mathrm{SiC}$ substrate and polishing pad were both immersed into the slurry, and the specimen surface was abraded by the polishing pad. The experiments were divided into four groups: (1) DOAP of RS-SiC for $6 \mathrm{~h}$ (oxidation $3 \mathrm{~h}$ followed by polishing $3 \mathrm{~h}$ ), (2) SOAP of RS$\mathrm{SiC}$ for $3 \mathrm{~h}$, (3) DOAP of $4 \mathrm{H}-\mathrm{SiC}$ for $2 \mathrm{~h}$ (oxidation $1 \mathrm{~h}$ followed by polishing $1 \mathrm{~h}$ ), and (4) SOAP of $4 \mathrm{H}-\mathrm{SiC}$ for $1 \mathrm{~h}$.

\section{Analysis of oxidation behaviors}

The oxidation behavior of RS-SiC observed by SEMEDX is shown in Fig. 2a-d. Figure $2 a$, b shows the comparison of surface morphologies before and after anodic oxidation at the same position. Figure $2 \mathrm{c}$, d shows the detailed surface morphology and the corresponding oxygen element distribution. It is interesting to note that there are few scratches on the anodic oxidized surfaces, although the initial surfaces, which are prepared by diamond lapping, have many scratches, as shown in Fig. 2a. We hypothesize that there are two reasons for the disappearance of scratches on the oxidized RS-SiC surface. First, the area with scratches has a larger surface area than the other areas, and the oxidation of RS-SiC increases its volume; thus, the scratches are closed by the expanded oxide. Second, the area surrounding that with scratches has a higher oxidation rate because of lattice strain; thus, the rapidly expanding oxide will fill the scratches. Through the closing and filling of scratches by anodic oxidation, scratches are eliminated on the oxidized RS-SiC surface. From the observation results in Fig. 2a, $\mathrm{b}$, it could be found that the $\mathrm{SiC}$ domains have a higher oxidation rate than the $\mathrm{Si}$ domains, which can be clearly concluded from the oxygen element distribution in Fig. 2d. We had also investigated the anodic oxidation of single-crystal $\mathrm{Si}$ and $4 \mathrm{H}-\mathrm{SiC}$ in our system. Under the same experimental conditions, it was observed that the oxidation rate of $4 \mathrm{H}-\mathrm{SiC}$ was slightly higher, whereas that of $\mathrm{Si}$ was much lower than that of RS-SiC. Moreover, for most anodic oxidized $\mathrm{SiC}$ grains, the boundary area has a higher oxidation rate than the central area. Meanwhile, for
Fig. 1 Schematic diagrams of experimental apparatus. a Anodic oxidation system. b Anodic oxidation polishing system

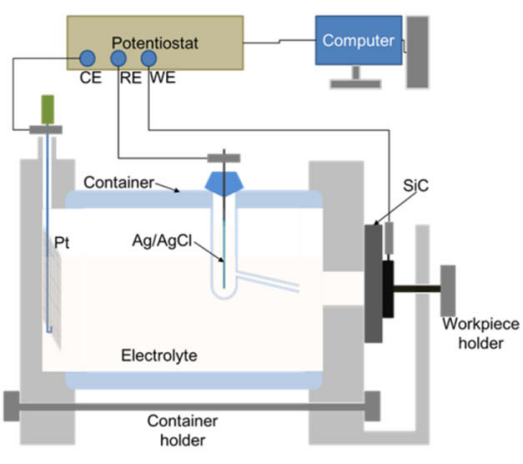

(a)

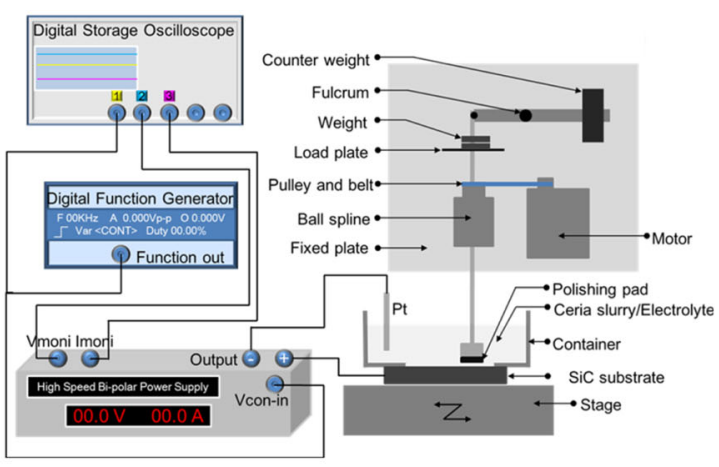

(b) 
Table 1 Experimental parameters in anodic oxidation polishing

Fig. 2 Anodic oxidation behaviors of RS-SiC observed by SEM-EDX. a Before anodic oxidation. b After anodic oxidation. c Details of oxide morphology. d Oxygen element distribution observed by EDX

\begin{tabular}{|c|c|c|c|c|}
\hline & Experiment 1 & Experiment 2 & Experiment 3 & Experiment 4 \\
\hline \multicolumn{5}{|l|}{ Specimen } \\
\hline Workpiece & RS-SiC & & $4 \mathrm{H}-\mathrm{SiC}$ & \\
\hline Size & Square, $50 \mathrm{~mm}$ & $\mathrm{~mm}$ & 1 in. & \\
\hline \multicolumn{5}{|l|}{ Electrolyte (slurry) } \\
\hline Abrasive size & Ceria, $\phi 190 \mathrm{nr}$ & & & \\
\hline Concentration & $0.1 \mathrm{wt} \%$ & & & \\
\hline \multicolumn{5}{|c|}{ Oxidation parameters } \\
\hline Potential & $10 \mathrm{~V}(\mathrm{DC})$ & & & \\
\hline Cathode & Platinum (Pt) & & & \\
\hline \multicolumn{5}{|c|}{ Abrasive polishing parameters } \\
\hline Polishing pad & K0017 (FILW] & . Ltd.) & & \\
\hline Pad size & Round, $\phi 10 \mathrm{~m}$ & & & \\
\hline Load & $30 \mathrm{~g}$ & & $150 \mathrm{~g}$ & \\
\hline Pressure & $3.75 \mathrm{kPa}$ & & $18.75 \mathrm{kPa}$ & \\
\hline Rotation speed & $300 \mathrm{rpm}$ & & & \\
\hline Scan speed & $5 \mathrm{~mm} / \mathrm{s}$ & & & \\
\hline Experimental time & DOAP for $6 \mathrm{~h}$ & SOAP for $3 \mathrm{~h}$ & DOAP for $2 \mathrm{~h}$ & SOAP for $1 \mathrm{~h}$ \\
\hline
\end{tabular}
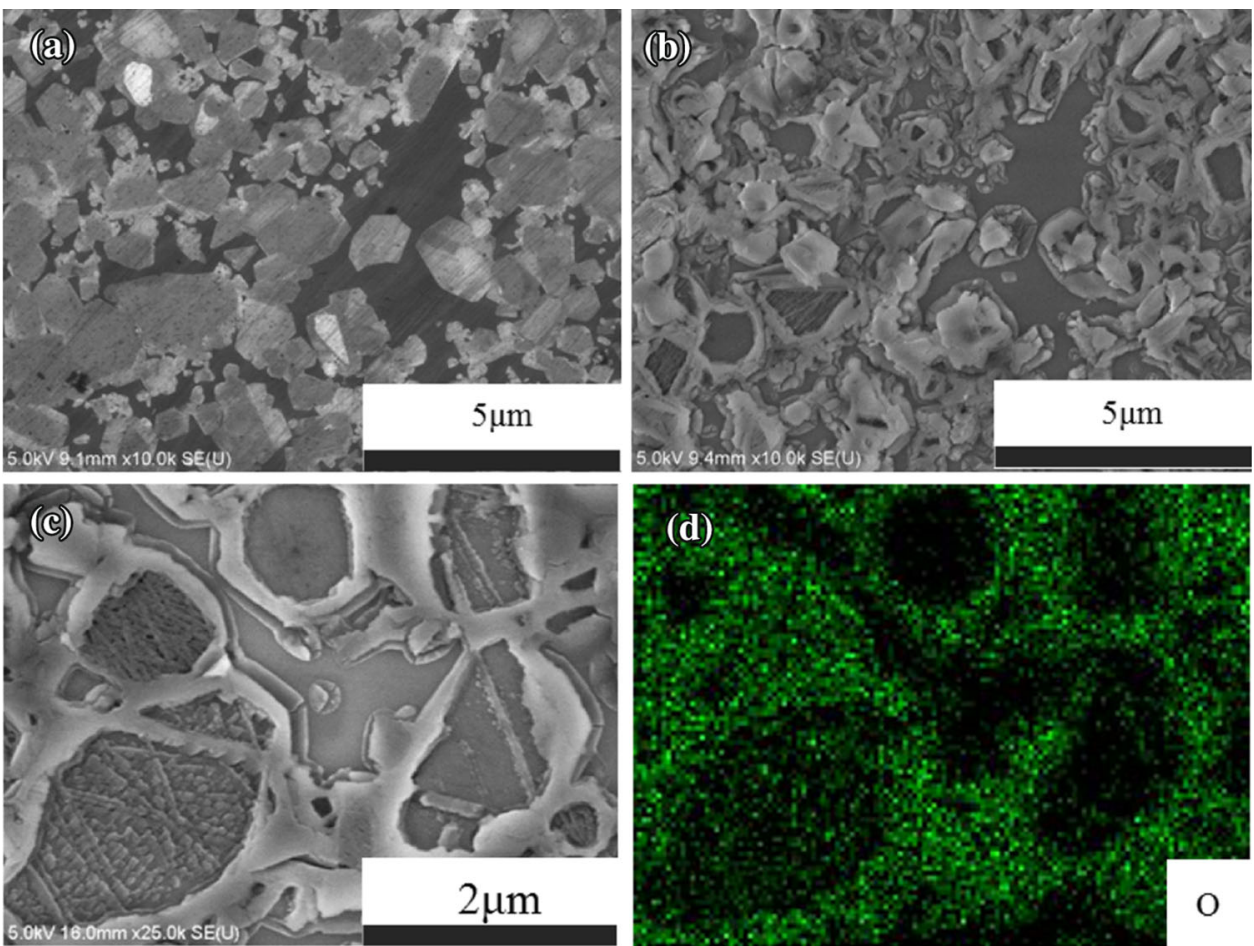

all anodic oxidized $\mathrm{Si}$ domains, the oxide surface is smooth. We hypothesize that it is because the electric properties and crystal lattices of $\mathrm{SiC}$ and $\mathrm{Si}$ differ. Furthermore, there were many cracks and projections on the anodic oxidized RS-SiC surface. We hypothesize that it is because the oxidation of $\mathrm{Si} / \mathrm{SiC}$ to $\mathrm{SiO}_{2}$ is a volume expansion process, and the swelling pressure is generated in both the thickness direction and the plane direction. The distribution of this pressure generated by an oxidized grain is determined by the oxidation rate distribution of the grain. Therefore, in the thickness direction, the pressure ejects the oxide, resulting in the formation of projections; in the plane direction, the pressure presses the neighboring grains, introducing cracks in the weak areas. 
Fig. 3 Anodic oxidation behaviors of $4 \mathrm{H}-\mathrm{SiC}$ observed by SEM. a Position 1 . b Position 2
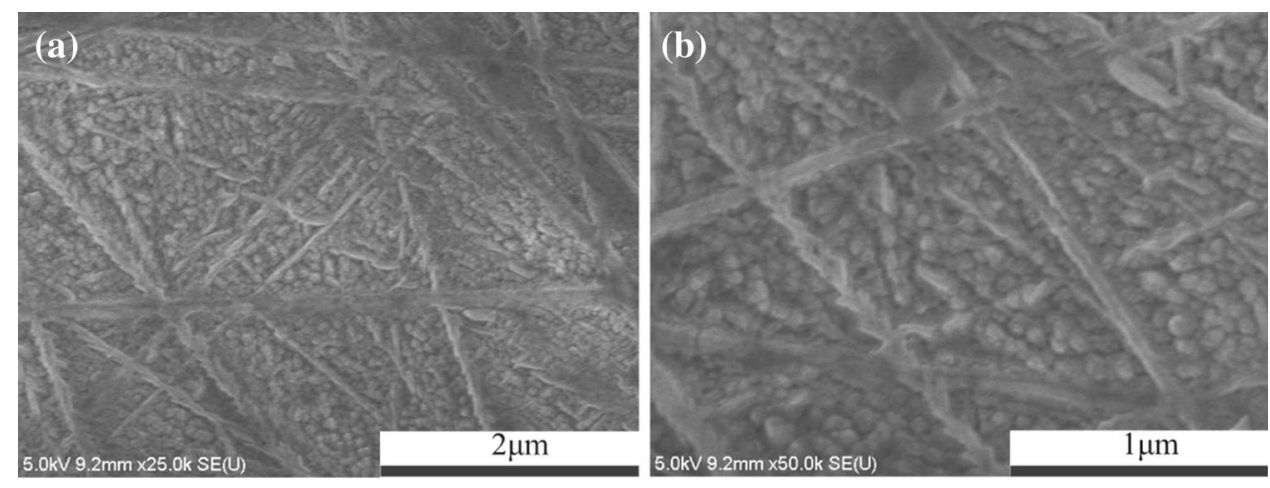

Fig. 4 Anodic oxidation behaviors of $4 \mathrm{H}-\mathrm{SiC}$ analyzed by AFM. a Position 1 . b Position 2

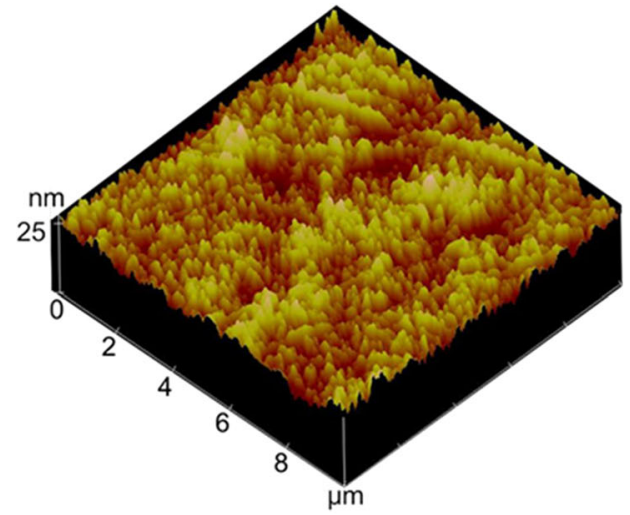

(a)

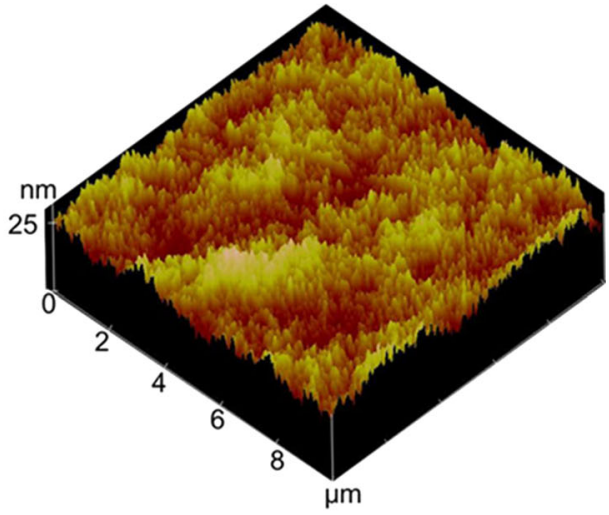

(b)
The oxidation behavior of $4 \mathrm{H}-\mathrm{SiC}$ obtained by SEM and AFM observation is shown in Figs. 3 and 4. From the SEM and AFM images, it was observed that there were many oxide protuberances on the oxidized surface, and the scratches on the original surface which are introduced by diamond lapping change into linear swellings. That's because the oxidation of $\mathrm{SiC}$ is a volume expansion process; thus, the scratches are filled by the bulgy oxides, and the oxidized $4 \mathrm{H}-$ $\mathrm{SiC}$ surface is covered with bulgy oxides. Comparing with the anodic oxidation behaviors of $\mathrm{RS}-\mathrm{SiC}$, there are few cracks or projections on the anodic oxidized $4 \mathrm{H}-\mathrm{SiC}$ surface. Although the swelling pressure is also generated by the volume expansion in the anodic oxidation of $4 \mathrm{H}-\mathrm{SiC}$, it is limited in the thickness direction. Meanwhile, the oxidation behaviors of some $\mathrm{SiC}$ grains in the anodic oxidation of RS$\mathrm{SiC}$ are different from that of $4 \mathrm{H}-\mathrm{SiC}$, because the crystal directions of each SiC grains in RS-SiC differ.

\section{Calculation of oxidation rate}

Through the scanning white light interferometry (SWLI) measurements and comparing the surfaces before and after $\mathrm{HF}$ etching of the anodic oxidized $\mathrm{SiC}$ samples, the oxidation depth corresponding to a certain oxidation time for
RS-SiC and 4H-SiC was obtained, respectively, as shown in Figs. 5a-e and 6a-e, respectively. Moreover, the summarized data for RS-SiC are shown in Fig. $5 f$ and that for 4H-SiC are shown in Fig. 6f, respectively. It can be obviously observed that the oxidation depth is larger with increasing in oxidation time.

From the SWLI measurement results, it can be calculated that the average anodic oxidation depth of RS-SiC corresponding to certain oxidation times of $5,10,20,30$, $45,60,120,180,300,600,900,1200$, and $1800 \mathrm{~s}$ is 25,38 , $47,58,62,68,88,102,120,135,145,156$, and $163 \mathrm{~nm}$, respectively, and the average anodic oxidation depth of $4 \mathrm{H}-$ $\mathrm{SiC}$ corresponding to certain oxidation times of 30,60 , 180,300 , and $1800 \mathrm{~s}$ is $63,107,170,236$, and $457 \mathrm{~nm}$, respectively. Through data fitting (isolated singularities were filtered) based on the Deal-Grove model [15], the relationship between oxidation depth $x(\mathrm{~nm})$ and oxidation time $t$ (s) for RS-SiC is shown in Eq. 1 and that for $4 \mathrm{H}-\mathrm{SiC}$ is shown in Eq. 2, respectively.

$t=0.01 x_{\mathrm{RS}-\mathrm{SiC}}^{2}+0.19 x_{\mathrm{RS}-\mathrm{SiC}}$

$t=0.0047 x_{4 \mathrm{H}-\mathrm{SiC}}^{2}+0.1729 x_{4 \mathrm{H}-\mathrm{SiC}}$

From the equations, it can be concluded that the oxidation rate can be $5.3 \mathrm{~nm} / \mathrm{s}$ for $\mathrm{RS}-\mathrm{SiC}$ and $5.8 \mathrm{~nm} / \mathrm{s}$ for 


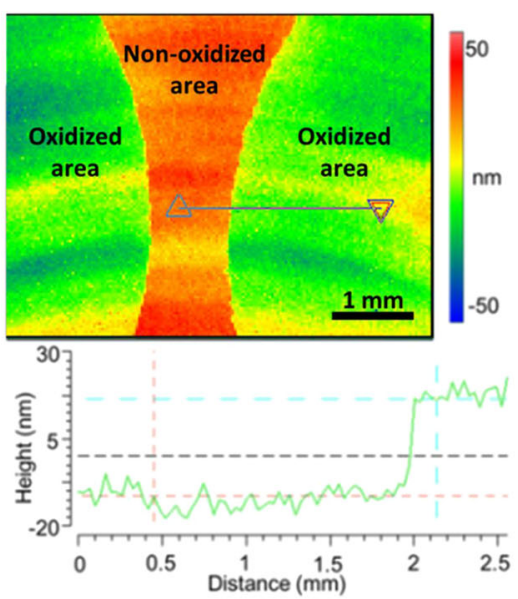

(a)

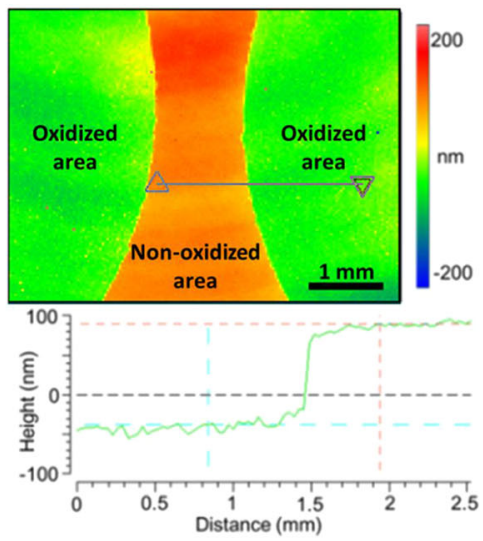

(d)

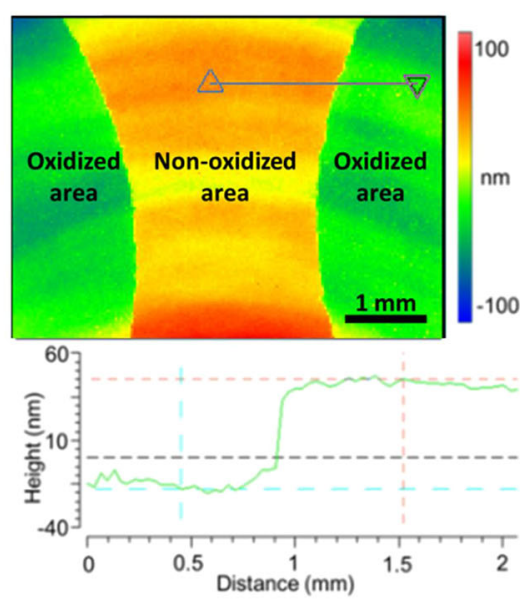

(b)

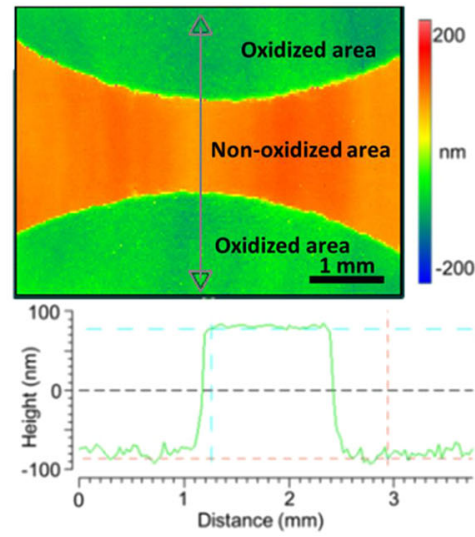

(e)

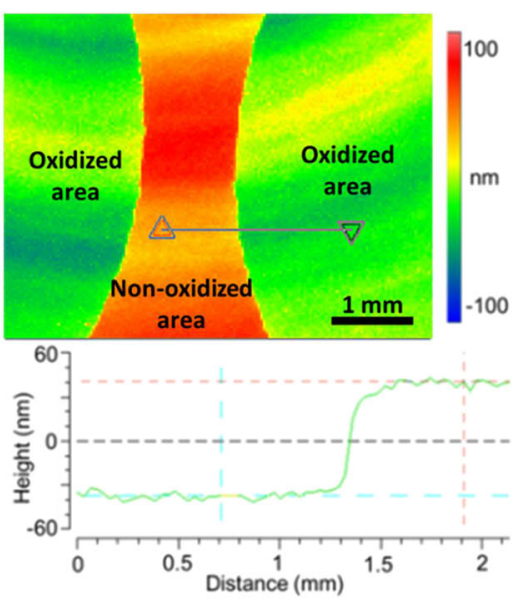

(c)

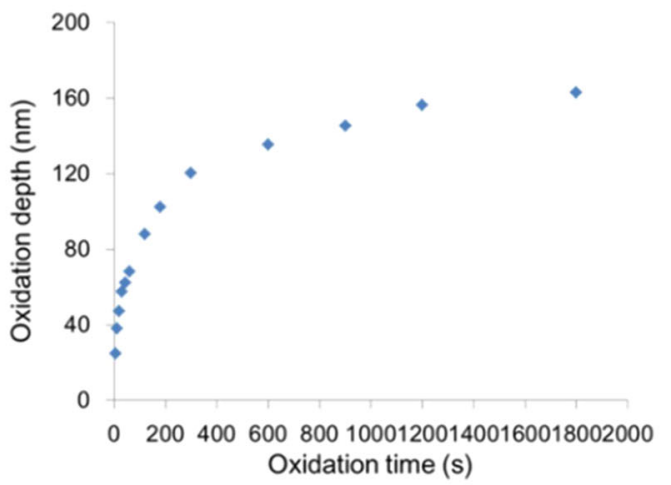

(f)

Fig. 5 Measurement of anodic oxidation depth of RS-SiC by SWLI. a Oxidation for 5 s. b Oxidation for 20 s. c Oxidation for 60 s. d Oxidation for $600 \mathrm{~s}$. e Oxidation for $1800 \mathrm{~s}$. f Oxidation depth and oxidation time

4H-SiC in the linear Deal-Grove model [15]. Therefore, if we conduct SOAP of SiC, the MRR would be $318 \mathrm{~nm} / \mathrm{min}$ for $\mathrm{RS}-\mathrm{SiC}$ and $348 \mathrm{~nm} / \mathrm{min}$ for $4 \mathrm{H}-\mathrm{SiC}$, which were hundred times of those in CMP $(<500 \mathrm{~nm} / \mathrm{h})$ [9], PAP $(<200 \mathrm{~nm} / \mathrm{h})$ [10], and CARE $(100-200 \mathrm{~nm} / \mathrm{h})$ [11].

\section{Comparative analysis of polishing property}

We conducted the anodic oxidation polishing of RS-SiC and $4 \mathrm{H}-\mathrm{SiC}$ by the system shown in Fig. 1b. The surface roughnesses rms of RS-SiC substrate after the conducted four scenarios were measured by SWLI and are summarized in Fig. 7a-d, and those of $4 \mathrm{H}-\mathrm{SiC}$ are summarized in Fig. $8 \mathrm{a}-\mathrm{d}$. The original surfaces which were prepared by diamond lapping had many scratches, as shown in Figs. 7a and $8 \mathrm{a}$, because the hardness of diamond is larger than that of $\mathrm{SiC}$ substrates. After anodic oxidation, the rms roughness of surface was deteriorated, as shown in Figs. 7b and $8 \mathrm{~b}$, since there were undulations and fluctuations resulting from the bulgy oxide.

The original $\mathrm{SiC}$ samples which were prepared by diamond lapping had many scratches, since the hardness of diamond is larger than that of $\mathrm{SiC}$. After anodic oxidation, both the RS-SiC and $4 \mathrm{H}-\mathrm{SiC}$ surfaces were deteriorated, because there are undulations and projections on the oxidized surfaces. The rms roughnesses of RS-SiC surface after SOAP were improved to $2.103 \mathrm{~nm}$ and that of $4 \mathrm{H}-\mathrm{SiC}$ were improved to $0.892 \mathrm{~nm}$, as shown in Fig. $7 \mathrm{c}, \mathrm{d}$, which were better than those after DOAP, as shown in Figs. 7d and 8d. The experiment results indicated that anodic oxidation polishing of $\mathrm{SiC}$ substrates 


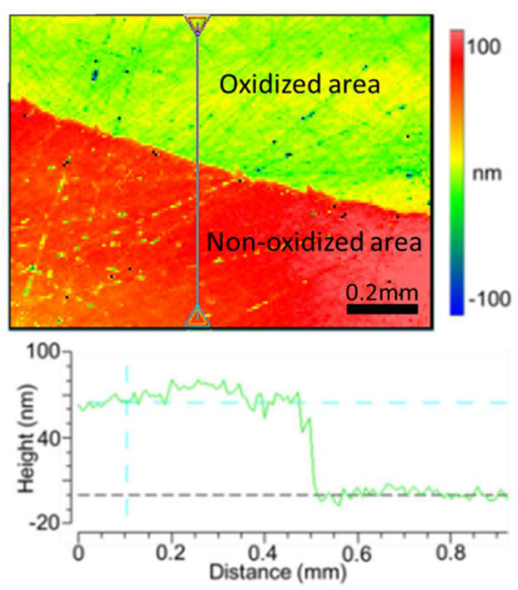

(a)

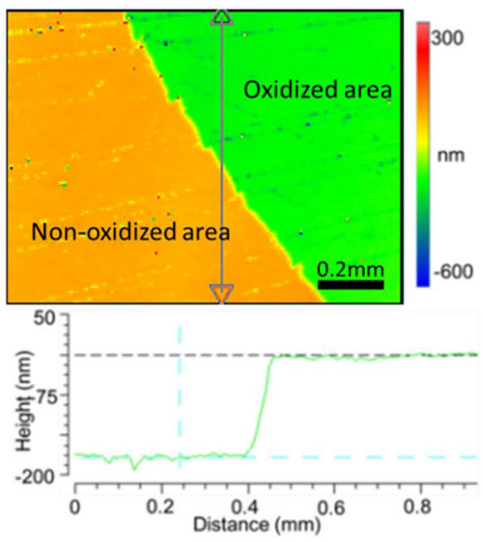

(d)
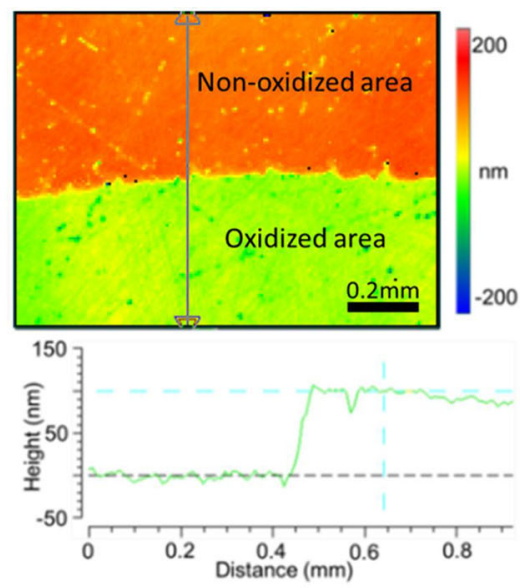

(b)
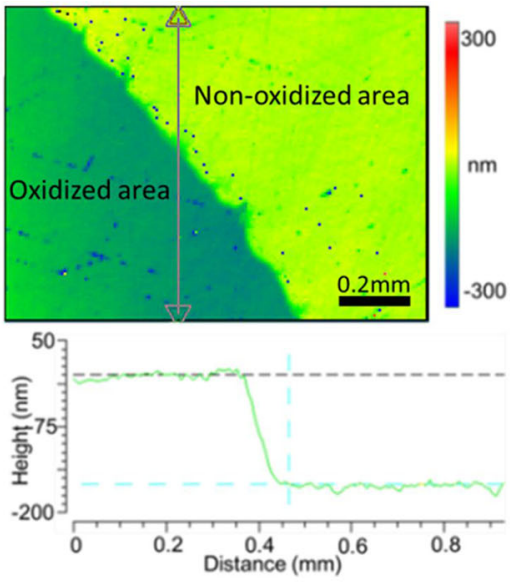

(c)

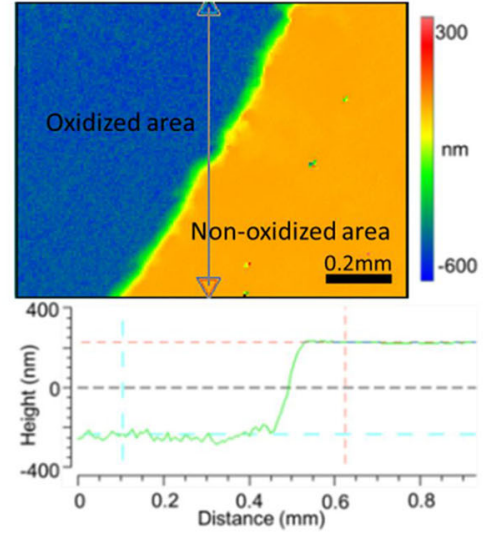

(e)

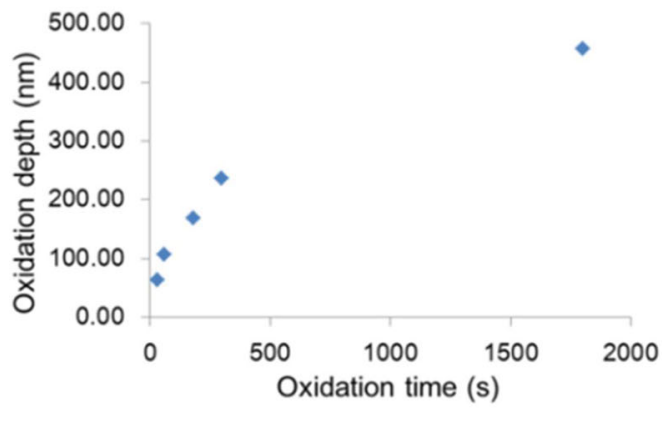

(f)

Fig. 6 Measurement of anodic oxidation depth of $4 \mathrm{H}-\mathrm{SiC}$ by SWLI. a Oxidation for $30 \mathrm{~s}$. b Oxidation for $60 \mathrm{~s}$. c Oxidation for $180 \mathrm{~s}$. d Oxidation for $300 \mathrm{~s}$. e Oxidation for $1800 \mathrm{~s}$. f Oxidation depth and oxidation time

can obtain high MRR and fine roughness simultaneously by SOAP.

\section{Summaries}

In this study, we conducted a comparative analysis of anodic oxidation polishing of $\mathrm{RS}-\mathrm{SiC}$ and $4 \mathrm{H}-\mathrm{SiC}$. The following conclusions were obtained.

1. For the research on the anodic oxidation of RS-SiC and 4H-SiC substrates, anodic oxidation system and anodic oxidation polishing system were constructed.

2. Anodic oxidation behaviors of $\mathrm{SiC}$ substrates were investigated by SEM-EDX observation and AFM analysis. Characters of the oxide on the oxidized $\mathrm{SiC}$ samples were expressed, which would promote the understanding of the anodic oxidation mechanism for $\mathrm{RS}-\mathrm{SiC}$ and $4 \mathrm{H}-\mathrm{SiC}$.

3. By SWLI measurements and comparing the surfaces before and after $\mathrm{HF}$ etching of the oxidized $\mathrm{SiC}$ samples, the oxidation depths corresponding to a certain oxidation time were obtained. Through data fitting based on the Deal-Grove model, the high MRR in anodic oxidation polishing of $\mathrm{SiC}$ substrates was forecasted.

4. Polishing properties of anodic oxidized $\mathrm{SiC}$ samples were analyzed by SWLI measurements. The surface roughnesses rms after SOAP of RS-SiC were improved to $2.103 \mathrm{~nm}$ and that of $4 \mathrm{H}-\mathrm{SiC}$ were to $0.892 \mathrm{~nm}$, 
Fig. 7 Comparison of surface roughnesses in anodic oxidation polishing of RS-SiC by SWLI. a Original surface obtained by diamond lapping. b Anodic oxidized surface. c Surface obtained by SOAP for $3 \mathrm{~h}$. d Surface obtained by DOAP for $6 \mathrm{~h}$

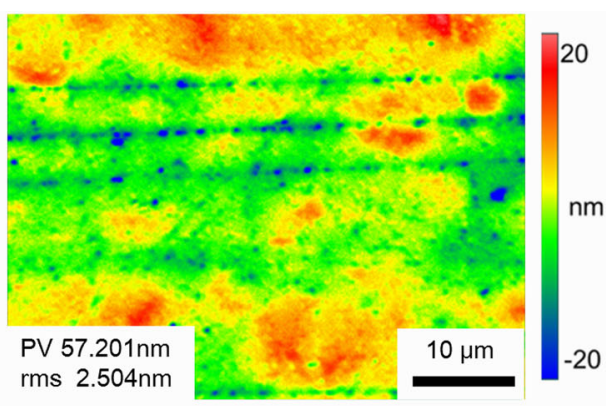

(a)

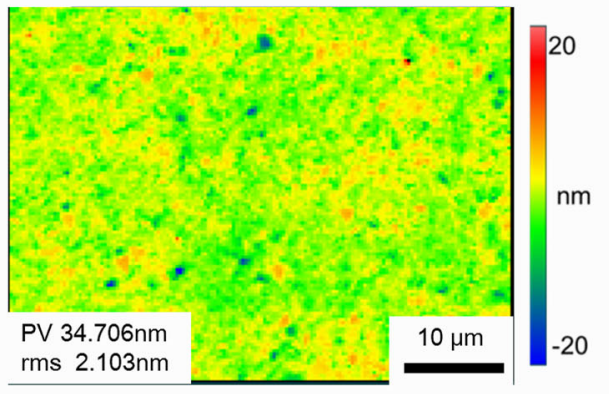

(c)

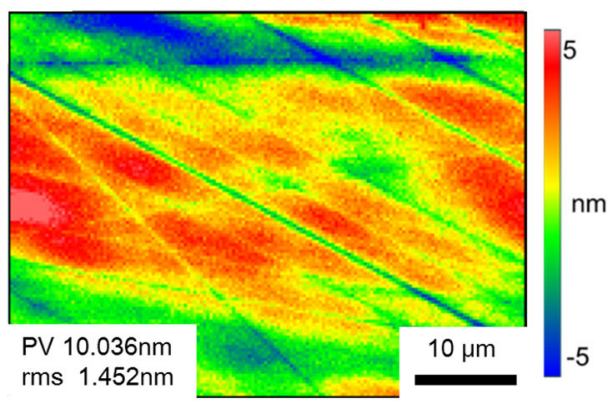

(a)

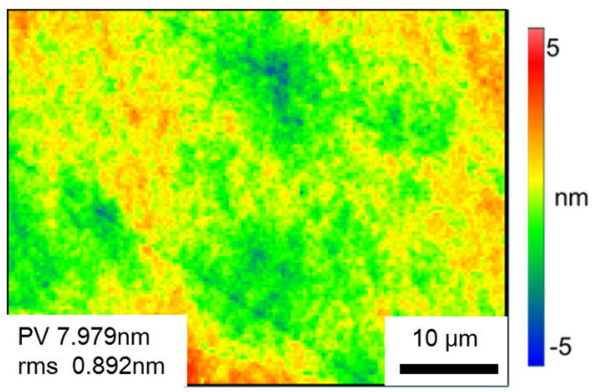

(c)

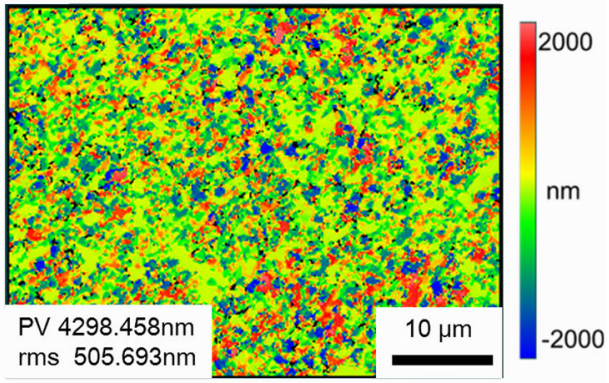

(b)

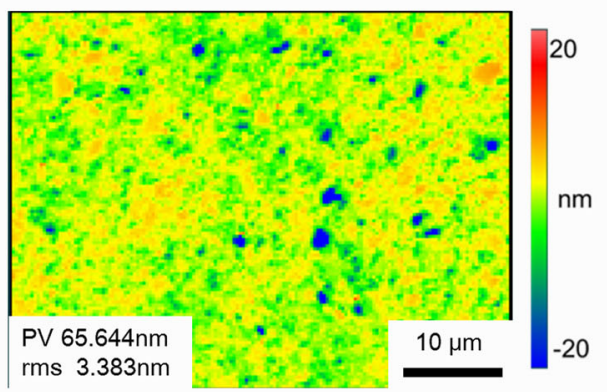

(d)

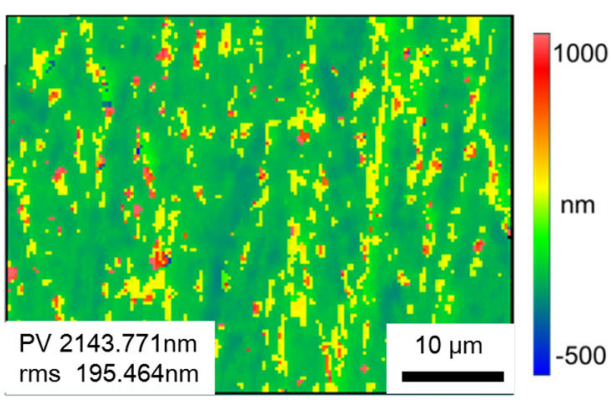

(b)

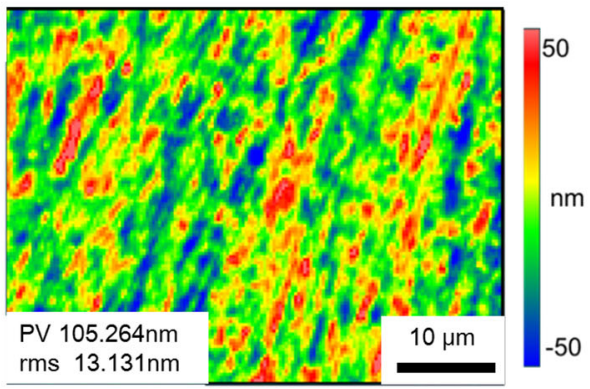

(d) which indicated that the anodic oxidation polishing of SiC substrate can obtain high MRR and fine surface roughness simultaneously by SOAP.

Anodic oxidation polishing would improve the machining level of $\mathrm{SiC}$ substrates and promote the application of $\mathrm{SiC}$ products in semiconductors, optics, and ceramics fields.

Acknowledgments This work was supported by a Grant from National Natural Science Foundation of China (Grant No. 51505498) and a Grant from Natural Science Foundation of Jiangsu Province 
(Grant No. BK20150714). The authors also express their gratitude to the staffs and students of the Research Center for Ultra-Precision Science and Technology of Osaka University.

Open Access This article is distributed under the terms of the Creative Commons Attribution 4.0 International License (http://crea tivecommons.org/licenses/by/4.0/), which permits unrestricted use, distribution, and reproduction in any medium, provided you give appropriate credit to the original author(s) and the source, provide a link to the Creative Commons license, and indicate if changes were made.

\section{References}

1. Z.Y. Zhang, J.W. Yan, T. Kuriyagawa, Int. J. Adv. Manuf. Technol. 57, 117 (2011)

2. H.Y. Tam, H.B. Cheng, Y.W. Wang, J. Mater. Process. Technol. 192-193, 276 (2007)

3. S. Suyama, T. Kameda, Y. Itoh, Diam. Relat. Mater. 12, 1201 (2003)

4. S.Q. Ding, S.M. Zhu, Y.P. Zeng, D.L. Jiang, J. Eur. Ceram. Soc. 27, 2095 (2007)
5. Z.R. Huang, G.L. Liu, X.J. Liu, Z.M. Chen, D.L. Jiang, Proc. SPIE 8335, 83351R (2012)

6. H. Zhu, X.L. Liu, D.Y. Yan, P. Ma, Proc. SPIE 8194, 81942A (2011)

7. X.C. Luo, S.G. Robert, L. Reuben, J. Eur. Ceram. Soc. 32, 3423 (2012)

8. Y. Dai, Int. J. Comput. Appl. Tech. 29, 145 (2007)

9. H. Nitta, A. Isobe, P.J. Hong, T. Hirao, Jpn. J. Appl. Phys. 50, 046501 (2011)

10. H. Deng, T. Takiguchi, M. Ueda, A.N. Hattori, N. Zettsu, K. Yamamura, Jpn. J. Appl. Phys. 50, 08JG05 (2011)

11. A.N. Hattori, T. Okamoto, S. Sadakuni, J. Murata, K. Arima, Y. Sano, K. Hattori, H. Daimon, K. Endo, K. Yamauchi, Surf. Sci. 605, 597 (2011)

12. X.M. Shen, Y.F. Dai, H. Deng, C.L. Guan, K. Yamamura, Opt. Express 21, 14780 (2013)

13. J. Yan, Z. Zhang, T. Kuriyagawa, Int. J. Mach. Tools Manuf 49, $366(2009)$

14. X.M. Shen, Y.F. Dai, H. Deng, C.L. Guan, K. Yamamura, Opt. Express 21, 26123 (2013)

15. B.E. Deal, A.S. Grove, J. Appl. Phys. 36, 3770 (1965) 